\title{
Who Narrates a Video Game?
}

\section{Hoedt, Madelon. Narrative Design and Authorship in \\ Bloodborne: An Analysis if the Horror Videogame. McFarland \& Company, 2019. pp. 214.}

Most of the video games are known primarily through their development teams. Although the video game industry became a more lucrative and influential art form than all other forms of entertainment combined, there still exists a lack of identification of video game products with their authors, directors, and/or writers. For example, The Last of Us is a game people will more often associate with developer team Naughty Dog than with Jacob Minkoff; the video game company SEGA is labeled as the team behind Sonic the Hedgehog, while the question of original creators remains unclear and often on the fringe. This way, many individuals are ostracized from their work, with only their biggest fans caring for some video game director's style, his/her narrative strategies, and composition. However, some video game creators are always clearly connected to their work, sometimes even being the main argument why a certain game is deserving of attention and praise. Hideo Kojima, for example, is one of the most recognizable, if not the most renowned director and video game designer, whose every game (although developed in detail by many other people) is seen through the lenses of his vision and style. Many gamers today know what to expect from these kinds of games, primarily due to highly popular and influential Metal Gear series. Although the situation somewhat changed during the past ten years, with more and more games getting profiled thought their authors, such as, for example, Yoko Taro or Yoshinori Kitase, the issue of authorship and how author's vision in ergodic literature can coexist with player's interactivity is still something that needs to be explored in more detail.

Madelon Hoedt, as an "academic and researcher, as well as a gamer" (6), reflects on the authorship in video-games, particularly on the immensely popular action RPG title - Bloodborne. 
Developed by Hidetaka Miyazaki, Bloodborne is one of the games considered to belong to extremely hard, and atmospheric RPG titles commonly labeled as Souls games. The name is based on Miyazaki's previous titles, the Dark Souls series, having similar combinations of difficult fights, atmospheric locations, and immersive lore that somewhat depends on the player's interest in exploring it in detail. Hoedt's focus on Bloodborne lies specifically in how it is influenced by literary works of authors H. P. Lovecraft and Bram Stoker, as well by the Gothic architectural design evident in the design of the fictional city of Yharnam. In addition, the narrative design Hoedt is presenting in the book differs from previous Miyazaki's work, primarily due to various elements in the game (items, texts, and location) that become more embedded in the story than is often experienced in other titles. By providing these ways of experiencing the story through the player's independent and diverse levels of involvement, Miyazaki, in a way, becomes cloistered from the authorship of Bloodborne. Bloodborne is undoubtedly a character-driven story, as Hoedt points out, mostly in Lovecraftian fashion, abounding with various ways of obtaining information about what exactly is going on with the Hunter, the character whom the player controls in the game. However, the spatial aspect of the game - stories behind various locations beneath or beyond the Yharnam surface, usage of various gameplay mechanics - present the players with different ways in which Miyazaki transfers the responsibility of the story to them. The versatility embodied in many elements throughout the game, which players may or may not acknowledge and explore, makes them the co-authors of the story. Hoedt, thus, focuses on explaining the mechanics and logic behind this kind of narrative design by meticulously analyzing various aspects of the game.

Her book, Narrative Design and Authorship in Bloodborne, presents how the interconnectedness of the video game's narrative, author's visions, and players' limitations, in the interaction between various elements containing information about the game's story, provides an area for a specific reading of Bloodborne. The book is a part of the Studies in Gaming book series issued by McFarland \& Company, and it is one of the rare ones focused exclusively on a single video game. By going along (and beyond) common academic writing about gaming communities and the influence video games may have on people playing them, Hoedt's approach is primarily inspired by and closely related to literary studies. This is understandable since the main problem addressed in Hoedt's analysis is Miyazaki's authorship and how his vision can be linear and categorical when 
the game, in its core, provides many interconnected elements for comprehending and consuming the story, dependent solely on the players' choices in acquiring all knowledge the game offers.

Even though a player can simply run, train, collect items and try to kill every enemy in sight, and finish the game through trial and error, many other elements in the game rely on players activities and "reading" that would make one fully understand his/her role in the game, the story, and the world in which he/she operates. For this reason, according to Hoedt, Miyazaki's role as an auteur is drastically diminished - intentional on Miyazaki's part - and shifted to the players, their choices, and inclusion in the narrative elements presented in the game. Bloodborne almost demands exploration, finding hidden areas in the game, and unraveling the role of characters, monsters, as well as the main aim of the game, or better said, the purpose of the main character (The Hunter). In a way, according to Hoedt, the player becomes the auteur.

In order to offer a detailed insight into these issues, Hoedt breaks her study down into three main parts - Lore, World, and Mechanics. This way, she introduces a new way of understanding the lore and lure of Bloodborne, and the ways in which it is delivered to the players/readers to help them unravel the narrative hidden behind the basic premise and tasks imposed on a general level.

The first part of the book, dedicated to the game's lore, is divided into three chapters - Hunters, Healer and Kin. Employing the close reading and semiotic approach, Hoedt explains the ways in which Bloodborne is constructed as a narrative puzzle; the pieces scattered throughout the game making "the process of meaning-making" (17) a vital part of the narrative experience. The first chapter concentrates on three factions: the Hunters, the Healing Church, and the Kin, further divided into sections under the same name, in which Hoedt analyses not only the cut scenes and main (unavoidable) parts of the story but also the description of items and dialogues with NPCs (non-playable characters). This was primarily done to contextualize and extensively explain the ways in which the player engages in the process of meaning-making, a process Miyazaki's vision relies on in order for the reader to experience the whole (or most of) the story. Hoedt suggests that Salen and Zimmerman's concepts of the embedded and emergent narrative are vital in understanding the process of Bloodborne's story and how the "active role of the player" is the bridge between "the narrative left by the game designers for the players to find (and the ease with which they can be located), and the story beats that are uncovered by the player" (17). 
The second part of the book is divided into three chapters: City, Environs, and Nightmare. It is primarily focused on spatial analysis of Bloodborne, especially the city of Yharnam and other locations, which are a "part of the fragmented Gothic narrative" (97). Same as in the case of factions, Hoedt points out how the so-called environmental storytelling and worldbuilding of a game play an important role in understanding and experiencing Bloodborne's lore. Again, the issue of coauthorship is emphasized since additional stories can be experienced through what Hoedt calls environs - "outliners of Yharnam" (109), the places dislocated from the main narrative but providing additional insights on the story.

She crystalizes the influence of Gothic and horror literature on Miyazaki and his creation of the lore that gains more attention as the book goes on, especially in the third part of the book, divided into three chapters: Insight, Echoes, and Dreams. Through gothic spaces in the game (analyzed in the previous section), Bloodborne presents a different kind of exploration of the game and narrative development that not only addresses what the story tells but also how (140). This way, one of the most engaging aspects of the book is about game mechanics, the ways in which it differs from other RPG titles, and how it is an asset for the narrativity of the game. In Hoedt's application of Bogost's notion of procedural rhetoric, she concentrates on how the game uses its mechanics to enforce the narrative formation. It is not just in the possible ways of playing and progressing in the game, and in the example of "Insights," we see the influence of H.P. Lovecraft, and the gothic genre in general, on Miyazaki's way of producing a distinct atmosphere for the players. Hoedt argues that there is a connection between H.P. Lovecraft's work and Miyazaki's vision of the worlds inhabiting the player. In the first part of the chapter, Hoedt explains how a game feature called "Insight," provides hidden knowledge to players. "Insight" is gained through exploration, defeating enemies, and summoning other real players to help you in battles, thus enabling the additional acquisition of knowledge, the new information about various story fragments explained in previous chapters. For Hoedt, this "[i]nformation is a necessity as Bloodborne relies on exploration, on its players' curiosity and their will to discover and piece together events" (146). She relates this procedural rhetoric with Lovecraft's philosophy and his approach to human knowledge residing in two spaces of existence: "Many of Lovecraft's fictions focus on moments in which the two planes bleed into one another, or weave their narrative around a human who may have received a 
glimpse of this other reality, and is now caught in a loop of (often desperate) attempts to make contact once more" (149).

As much as the game itself is immensely difficult (as all games within Soulsborne series of Hidetaka Miyazaki's design are) and in which players are left alone to figure out how to be better, how to fight and play, the same happens to the story. Different levels of players' immersiveness in the Bloodborne lore depend on their willingness to read different story fragments, and to research areas they inhabit in more detail.

For people not directly involved with Bloodborne, it is still an interesting work on the question of narrative, authorship, and videogames. While presenting her case study, Hoedt provides various sources and useful operationalization of the aforementioned topics. By placing it in the conscious limbo between Gothic, horror studies, and gaming studies, the book seeks readers within these fields, offering a vast amount of useful insights in return - its construction of "breach," of the different dimensions in which to acquire knowledge. As is the case with Bloodborne, Hoedt also provides us with a ground on which knowledge and end results are dependent on our strivings. For many scholars interested in video game narratives, Narrative Design and Authorship in Bloodborne is an essential read, as well as a great additional material in horror and gothic studies, regardless of the scholar's or student's interest in this particular game. Whether you played it or not, the book offers a way to go through it, or better said, through one of the various possible readings of Bloodborne's role and its influence on gaming, literary and narrative studies.

\section{() $\odot \odot$}

Creative Commons Attribution-NonCommercial-NoDerivatives 4.0 International License 